\title{
PERIPHERAL VASCULAR HEMODYNAMICS IN THE BULBAR CONJUNCTIVA OF SUBJECTS WITH HYPERTENSIVE VASCULAR DISEASE ${ }^{1,2,3}$
}

\author{
By RICHARD E. LEE AND ELIZABETH A. HOLZE \\ (From the Department of Medicine, The New York Hospital, and Cornell University Medical \\ Center, New York, N. Y.; and the Federal Security Agency, U. S. Public Health \\ Service, National Institutes of Health, National Heart Institute, Bethesda, Md.)
}

(Submitted for publication October 11, 1950; accepted, March 19, 1951)

Within recent years, methods have been developed for direct observational studies concerned with functional aspects of the muscular vessels in the capillary bed of living small mammals of several species (1-3). With these technics, it has been found that certain objective criteria of peripheral vascular reactivity can be selected and followed during repeated examinations of the terminal vessels with the microscope. Comparisons of the several different overall hemodynamic disturbances in the experimental animal (i.e., hypertension, acute hemorrhage, prolonged hypotension) with their co-existent phenomena in the peripheral vascular system have shown that each separate condition thus far investigated has had a distinctive status reflected in the capillary bed of the mesentery. For example, acute hemorrhage was accompanied by widespread arteriolar and metarteriolar constriction, capillary ischemia, and poor venular return. The reactivity of metarterioles and precapillary sphincters to topically applied epinephrine was augmented. Terminal prolonged hemorrhagic or traumatic hypotension, on the other hand, had a dilated capillary bed, with sluggish arteriolar and venular blood flow, plethoric capillaries and diminished epinephrine responses $(2,4,5)$. The mesenteric vascular bed in experimental renal hypertension was predominantly constricted, with ischemic arterioles and capillaries and a similar elevation of epinephrine response. In addition, it had a marked "hyperplasia" of vascular elements (6).

\footnotetext{
1 This work was supported in part by the Nutrition Foundation, New York, N. Y.

2 Apparatus used for the study of the conjunctiva was obtained through a grant in aid from the American Philosophical Society, Philadelphia, $\mathrm{Pa}$.

3 The authors gratefully acknowledge the stimulating interest and encouragement of Dr. Ephraim Shorr and , Dr. Benjamin William Zweifach.
}

It should be emphasized that no single feature of those which were selected to be followed in animals could be described as "characteristic" of any of these experimental syndromes. Vasoconstriction, or elevated epinephrine responses, or sluggishness of blood flow, etc., were often found in various and differing situations. The specificity of the hemodynamic state became apparent only when all of the functional criteria used were considered together.

The observational methods and technics of eliciting peripheral vascular responses to stimuli during examinations of the vessels with the microscope have been adapted, with modifications, to the study of metarterioles, capillaries and collecting venules in the conjunctiva of man. The description of the microscope and apparatus, which are comparable to those used by others (7), together with the procedures and observations on young adults without known disease, have been previously published (8). Since then the survey has been extended to include patients with hypertensive vascular disease. It is the purpose of this report to describe certain peripheral vascular hemodynamic responses in these patients and to compare them with findings in normotensive subjects.

\section{METHODS}

The technics employed in this study were those used and described in the previous report (8). In brief, the bulbar conjunctiva in each eye was examined with a slitlamp microscope in a manner similar to that used in routine ophthalmological practice. After establishing that conjunctival disease per se was absent, the general state of the capillary bed was noted (i.e., ischemic, plethoric, euvascular, etc.). In certain cases, the velocity of blood flow was measured in the metarterioles, capillaries and collecting venules with the method previously described (8). This procedure consisted of repeated determinations with an ocular micrometer in the microscope, and a fast stopwatch, of the durations of the passage of red 
blood cells over a measured length of vessel. At the magnifications used $(47 \times)$, single red blood cells, and cell aggregations can readily be seen and followed. In measurement of flow speed, vessels were selected (arterioles, capillaries and venules) that were as straight as could be found, over a distance of at least 75-100 microns. After a minimum of practice, the method has been found to furnish comparable data with different observers.

In a total of 30 subjects, the incidence of spontaneous vasomotor activity 4 in the precapillary sphincters was estimated. Metarteriolar and precapillary sensitivity to directly applied epinephrine in known concentration was then measured. It proved important to begin with the most diluted solution ( $1: 800,00-1: 400,000$ epinephrine) and use progressively stronger concentrations (at intervals of three minutes) until the threshold precapillary constrictions were obtained. This avoided possible sensitization of the vascular smooth muscle cells by repeated exposure to epinephrine solutions of greater than threshold strength. A vasoconstrictor response to cold can be measured by applying an ice pack to the closed lid for progressively greater intervals until precapillary constriction is seen. This type of response may also be tested by routine use of a short period of exposure to ice (10 seconds) which is without subsequent vascular change in a large series of controls, yet which is followed by vasoconstriction in certain disease states (cirrhosis, multiple myeloma). The latter method was employed in this study.

To date, examinations of the bulbar conjunctiva in hypertensive individuals have been made on 14 men and 31 women. The mean age was 31 years, with age distribution from three to 78 years. ${ }^{5}$ During repeated studies over periods of from two to three months, the blood pressures were consistenly greater than $140 / 100$ in all subjects. Only those cases were selected who had no history of renal or hepatic disease or cardiac incompetency. P.S.P. tests, urine concentrating and diluting capacities and blood urea nitrogen concentrations in all cases demonstrated no renal insufficiency. Intravenous pyelograms were carried out on 20 subjects and retrograde pyelograms were made on three others. These $\mathrm{X}$-rays revealed no evidence of renal abnormality.

In addition, similar conjunctival observations were made on 33 patients with various normotensive systemic diseases, such as multiple myeloma, cirrhosis, peptic ulcer, polycythemia; and with psychosomatic disorders. None of them had a history of hypertension. These cases had

${ }^{4}$ Vasomotion is an apparently spontaneous variation in caliber resulting from contraction and relaxation of the vascular smooth muscle. It is usually irregular in rate, in degree and in duration of dilated and constricted phases.

5 The Department of Pediatrics at Cornell University Medical College and The New York Hospital has been very interested and cooperative in this study. The authors are very grateful to the department, and to Dr. Sarah Matteson, for alerting them to the occasional occurrence of "essential hypertension" in early childhood, and for their cooperation in the project.

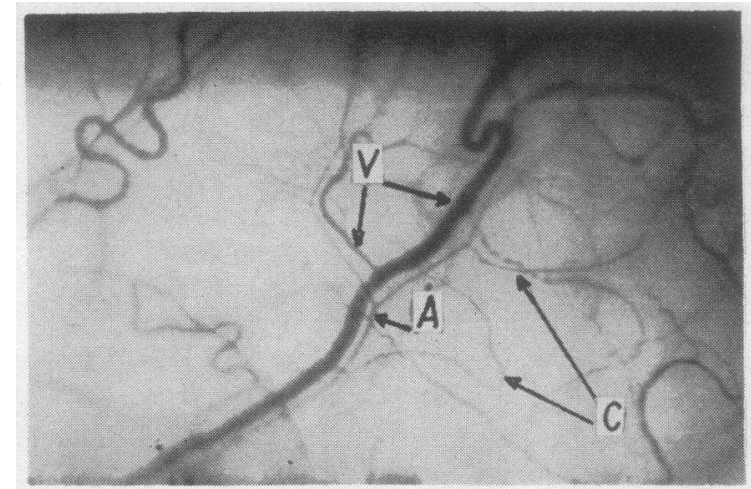

Fig. 1. The Conjunctival Capillary Bed of a Normotensive Subject without Disease

$A=$ terminal arteriole, from which the true capillaries (C) arise. These latter vessels are of uniform caliber and in general follow a smooth, sinuous pathway over the conjunctiva. Two capillaries in the right half of the picture, however, are slightly tortuous or coiled. The collecting venules (V) drain the capillaries, then form larger venules which are frequently situated approximate to the arteriole, as shown. The small venules in the left portion of the picture display the venular loopings which are not uncommon in normotensive individuals $(120 \times)$. (This is another photograph of the same field shown in Figure 1 of the previous publication.)

received a wide variety of clinic and laboratory studies. Those of each subject were appropriate only to his specific illness. The vascular findings in this group are therefore representative of a random sampling in a diseased population and are included only for the purpose of comparing their variability with the relatively consistent phenomena displayed by the blood vessels of the patients with "essential hypertension." The results of the survey on 72 normotensive subjects without evidence of disease are also included in the data.

\section{RESULTS}

The capillary bed and its reactions in the conjunctiva of normotensive subjects has been previously described (8). Its topographical arrangement in shown in Figures 1 and 2 . The terminal arterioles, usually accompanying larger collecting venules, frequently extend radially from the orbital margins. Capillaries arise from these vessels to form the blood capillary network of the conjunctiva. These vessels become confluent to form the most peripheral system of collecting venules, which in turn empty into the larger venules accompanying the nutrient arterioles (Figure 1).

The general nature of the circulatory state in the terminal vascular bed in hypertension was that 
of overall vasoconstriction. Metarterioles were notably more narrowed than those of controls; and occasionally they were actually smaller in diameter than were the true capillaries. This latter phenomenon is well known in lower animals and is believed to be the basis for earlier descriptions of "capillaries" (i.e., the smallest terminal vessels) as elements with contractile (muscle) cells along the endothelial wall. The increased narrowing was variable in different subjects, ranging from a difference noted only in two to three arterioles of each conjunctiva to a widespread vasoconstriction with pallor and closure of most of the precapillary sphincters. In general, the degree of vascular narrowing was correlated with the level of the diastolic pressure, for it was more pronounced in subjects with the greater diastolic elevations. It was noted also to be more severe, however, in patients with a hyperkinetic reaction pattern during interview.

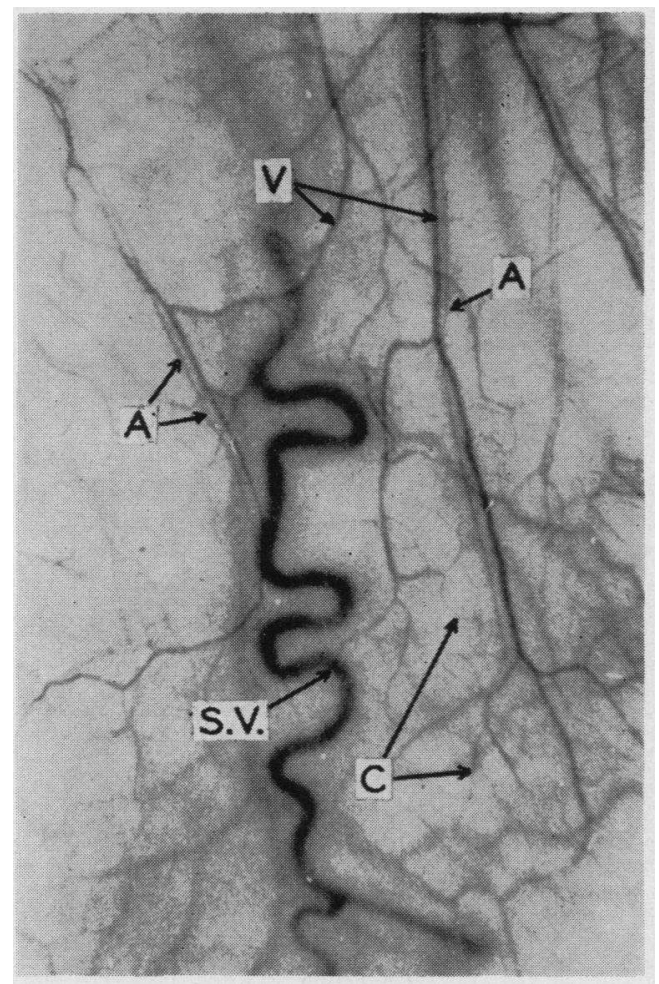

Fig. 2. Left Temporal Conjunctiva in Normotensive Subject without Other Disease, R. L., Aged 35

The metarterioles (A) are usually straight and are approximately one-half the diameter of the accompanying venules $(\mathrm{V})$. The true capillaries are seen here as fine slightly curved lines forming a regular pattern between the larger vessels. $(80 \times) \quad(\mathrm{S} . \mathrm{V} .=$ scleral vein, commonly of this tortuosity.)

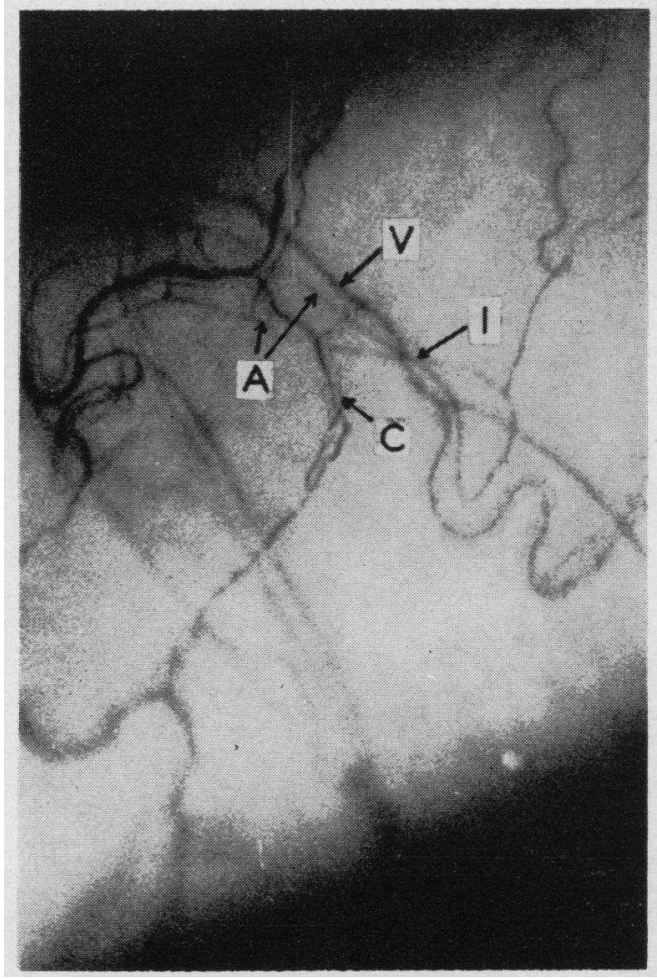

Fig. 3. Left Temporal Conjunctiva in Hypertensive Subject without Other Disease, G. H., Aged 3

The metarteriole (A) and the collecting venule (V) are moderately sinuous. The metarteriole (A) is completely looped (1), in contrast to the straight arteriolar pathway shown in Figure 2, and one capillary shows an irregularly serrate course $(C) .(80 \times)$

The vasoconstricted state was associated with a reduced velocity of blood flow in all observed arterioles, capillaries and venules. This was most readily seen in the true capillaries and collecting venules.

In 15 hypertensive patients, the occurrence of spontaneous vasomotor activity at precapillary sphincters was compared to that found in 12 control individuals and 12 patients with normotensive disease. In both normotensive and hypertensive subjects vasomotion varied in rate and in duration of the dilated and the constricted phases. In the hypertensives, in contrast to findings in all other subjects, it was more rapid with relatively long periods of precapillary narrowing. This resulted in intermittent, or interrupted, capillary blood flow. A sudden jet-like column of red cells would enter the capillary and flow would be uniform for several seconds. The stream was then gradually reduced as the precapillary narrowed, with subsequent 
longer periods during which only scattered red cells were admitted into the capillary from the parent arteriole.

The minimum concentration of epinephrine which produced threshold constrictions of the precapillaries and metarterioles in hypertensive patients was approximately $1 / 10$ the threshold strength necessary to produce constriction in similar vessels of normotensive individuals without other disease. A comparable elevation of the vascular reactivity to epinephrine has been observed to date only in cases of Laennec's cirrhosis and in patients with hyperglobulinemia. Subjects with these abnormalities constituted $45 \%$ of our control

TABLE I

Peripheral vascular findings in normotensive and in hypertensive subjects

\begin{tabular}{|c|c|c|c|c|}
\hline \multirow[b]{2}{*}{$\begin{array}{l}\text { General nature of the vascu- } \\
\text { lar system }\end{array}$} & \multicolumn{2}{|c|}{$\begin{array}{c}\text { Group I } \\
\text { Normotensive subjects without } \\
\text { known disease } \\
.(72)\end{array}$} & $\begin{array}{c}\text { Group II } \\
\text { Hypertensive vascular disease } \\
\end{array}$ & \multirow{2}{*}{$\begin{array}{l}\text { Group III } \\
\begin{array}{l}\text { Normotensive subjects with } \\
\text { various and differing diseases } \\
(33)\end{array} \\
\begin{array}{l}\text { Variable, from wide dilation } \\
\text { and sluggish flow, to euvas- } \\
\text { cular }\end{array}\end{array}$} \\
\hline & \multicolumn{2}{|c|}{$\begin{array}{l}\text { Vessels tonic; flow smooth } \\
\text { and rapid; no stagnation }\end{array}$} & $\begin{array}{l}\text { Vessels narrowed; tissue is- } \\
\text { chemic; flow slowed }\end{array}$ & \\
\hline $\begin{array}{l}\text { Spontaneous vasomotor ac- } \\
\text { tivity }\end{array}$ & \multicolumn{2}{|c|}{$\begin{array}{l}\text { Present up to grade } 1 \text { in } 3 \text { of } \\
12 \text { cases; variable in dura- } \\
\text { tion and frequency }\end{array}$} & $\begin{array}{l}\text { grade } 3-4 \text { in } 11 \text { of } 15 \\
\text { ases; rapid; "closed" phase } \\
\text { redominated }\end{array}$ & $\begin{array}{l}\text { Usually not seen; highly } \\
\text { variable }\end{array}$ \\
\hline \multirow{2}{*}{$\begin{array}{l}\text { Velocity of peripheral blood flow } \\
(\mathrm{mm} . / \mathrm{sec} .)\end{array}$} & \multicolumn{2}{|c|}{$(10)$} & $(10)$ & $(10)$ \\
\hline & Mean & $S . E$. & Mean & Mean \\
\hline 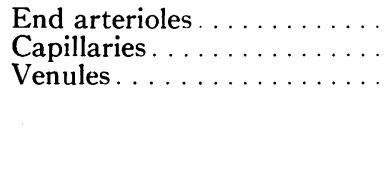 & $\begin{array}{l}0.11 \\
0.026 \\
0.056\end{array}$ & $\begin{array}{l}0.03 \\
0.002 \\
0.005\end{array}$ & $\begin{array}{l}0.023 \\
0.010 \\
0.018\end{array}$ & \begin{tabular}{c|c}
0.034 & 0.010 \\
0.008 & 0.004 \\
0.016 & 0.006 \\
Greatly reduced in all vessels \\
in cases of hyperglobulinemia \\
and some cases of cirrhosis
\end{tabular} \\
\hline $\begin{array}{l}\text { Coiling, tortuosity and loop- } \\
\text { ing of vessels }\end{array}$ & \multicolumn{2}{|c|}{$\begin{array}{l}\text { Up to grade } 1 \text { in } 8 \% \text { of sub- } \\
\text { jects }\end{array}$} & $\begin{array}{l}\text { Grade } 3-4 \text { in } 62 \% \text { of the } \\
\text { cases } \\
\text { Grade } 1-2 \text { in } 12 \% \text { of cases }\end{array}$ & $\begin{array}{l}\text { Up to grade } 1 \text { in } 18 \% \text { of sub- } \\
\text { jects }\end{array}$ \\
\hline $\begin{array}{l}\text { Epinephrine concentration } \\
\text { producing threshold pre-cap. } \\
\text { and metarteriolar narrowing }\end{array}$ & \multicolumn{2}{|c|}{$\begin{array}{l}\text { Mean-1:37,000 } \\
\text { S.E.-1:03,670 } \\
\text { Range-1:20,000-1:50,000 }\end{array}$} & $\begin{array}{l}\text { Mean-1:298,000 } \\
\text { S.E.-1:24,700 } \\
\text { Range-1:100,000-1:800,000 }\end{array}$ & $\begin{array}{l}\text { Mean-1:314,000 } \\
\text { S.E.-1:32,000 } \\
\text { Range-1:10,000-1:800,000 } \\
\text { Elevated above group } 1 \text { mean } \\
\text { only in Laennec's cirrhosis } \\
\text { and hyperglobulinemia to } \\
\text { date }\end{array}$ \\
\hline $\begin{array}{l}\text { Reaction to cold ice pack } \\
\text { application (15 sec.) }\end{array}$ & \multicolumn{2}{|c|}{ none } & $\begin{array}{l}\text { Grade } 1 \text { in } 7 \\
\text { Grade } 2 \text { in } 1\end{array}$ & $\begin{array}{l}\text { Variable, from no response } \\
\text { to a grade } 4 \text { vasoconstriction, } \\
\text { with stagnant flow and red } \\
\text { cell aggregates, in patients } \\
\text { with hyperglobulinemia }\end{array}$ \\
\hline $\begin{array}{l}\text { Effect of prior cold exposure } \\
\text { on epinephrine sensitivity }\end{array}$ & \multicolumn{2}{|c|}{ none } & none & $\begin{array}{l}\text { Increased in } 5 \text { cases of hyper- } \\
\text { globulinemia }\end{array}$ \\
\hline
\end{tabular}

The figures in parentheses indicate the number of patients studied. Unless otherwise indicated, determinations were carried out on all subjects. Spontaneous vasoconstriction, the reaction to cold, and the degree of abnormal capillary topography, are graded in ascending severity from 1 to 4 .

From the Table of $\mathrm{x}$, the differences in mean values for velocity of flow and epinephrine reactivity between the normal subjects of Group I and the disease groups are highly significant. A comparison of these two features is difficult, however, and not quite significant, between Groups II and III, because of the great reduction in flow speed and augmentation of epinephrine reactivity that was uniformly observed only in patients with hyperglobulinemia and certain cases of Laennec's cirrhosis, in the latter group. These wide specific variations, with the extremely heterogeneous nature of Group III, encumber statistical analysis of its flow speeds and vascular reactions. 
disease group. For this reason, the average vascular epinephrine reactivity in these non-hypertensive illnesses was also greatly elevated. This is in accord with the situation which obtains in the experimental animal, in that precapillary reactivity to epinephrine may be augmented in certain other states as well as in experimental hypertension.

A minimal vasoconstrictor response to topical cold (grade 1 or below) occurred in seven of 27 of the hypertensive patients. An eighth subject, a 10 year old boy, had a grade $2-3$ response to this test. Twelve of 21 patients with diseases other than hypertension had elevated vascular responses to cold (to grade 4) (Table I). Vasoconstriction in response to the cold stimulus used in this series was not observed in any of the normotensive nondiseased persons. Exposure to cold before the application of epinephrine to the conjunctival vessels

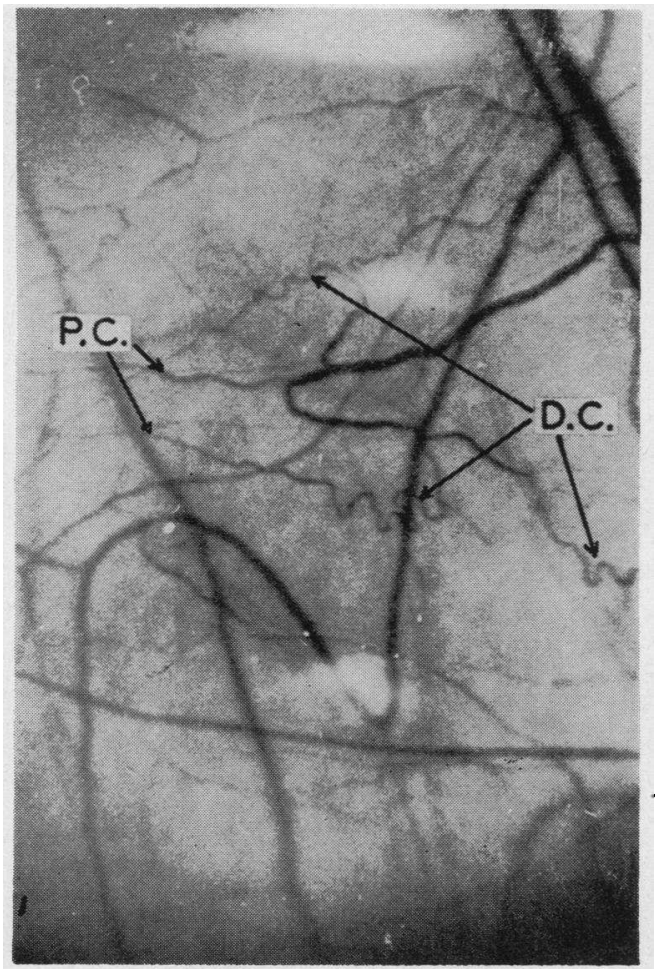

Fig. 4. Subject G. H. (As Figure 3)

The capillaries are shown at higher magnification to demonstrate the uniform nature of their proximal (arteriolar) portions (PC). The distal segments of the capillaries (DC) are tortuous and slightly coiled. $(120 \times)$ These changes shown in Figures 3 and 4 not only indicate the morphological abnormalities, but also demonstrate that they may exist in very young subjects with hypertension.

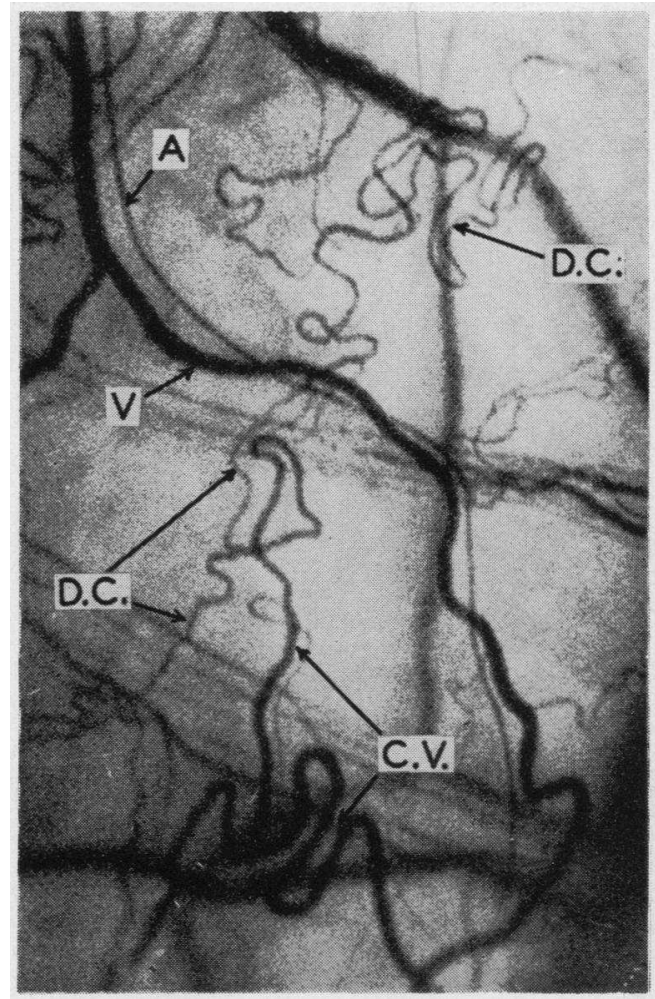

Fig. 5. Left Temporal Conjunctiva in Hypertensive Subject without Other Disease, M. C., Aged 37

The larger metarteriole (A) and venule (V) are relatively uniform. The distal capillary segments (DC) and the collecting venules (CV) are excessively coiled, looped and elongated in comparison with those of normotensive subjects shown in Figures 1 and 2. $(120 \times)$

had no detectable effect on the epinephrine response in any of the subjects excepting a small group of five normotensive patients with multiple myeloma.

In $62 \%$ of the hypertensive subjects, abnormal patterns of vascular topography, of grade 3 severity or greater, were observed. These consisted of tortuosity of arterioles and accompanying venules, with occasional looping and coiling of vessels in a striking manner (Figures 3-5). The capillaries in these cases were angular, looped and often tremendously elongated; and frequently followed a tortuous pathway over the conjunctiva (Figure 5). A somewhat comparable appearance of the vessels was noted in $18 \%$ of cases with normotensive disease, with slight coiling and tortuosity in several capillary vessels. In these latter subjects, however, it was of minimal degree (grade 1 or below). This unusual vascular pattern in hyper- 
tension frequently was of considerable magnitude in the conjunctiva of one eye and much less severe in the other. Tortuosity of the retinal arterioles and venules was also noted in many of the these hypertensive cases. This abnormality was found in three of these subjects to be largely unilateral in the retina as well.

Four individuals were examined who previously had been hypertensive. They were normotensive and asymptomatic at the time of study and had been so for periods of from four months to three years. The remission of hypertension was spontaneous in each instance. Three of the subjects had had "toxic" pregnancies, while the fourth was a 35 year old male who formerly had experienced only minor frontal headaches. None had any evidence of disease. The conjunctival metarterioles, however, were moderately constricted in all four cases, and peripheral vascular epinephrine sensitivities were consistently within the "hypertensive range." In addition, the conjunctival capillaries of two of these cases were tortuous and coiled (grade 3 ).

\section{DISCUSSION}

Studies of the mesenteric capillary bed in the experimental renal hypertension of rats and dogs in this laboratory have revealed certain consistent changes in the peripheral vessels. Following the proper application of Goldblatt clamps to the renal arteries or the use of perinephric silk packs, the arterial mean pressure rose gradually. Coincidentally, vasoconstriction developed in the terminal arterioles and spontaneous vasomotion became augmented $(6,9)$. The response of the metarterioles to topically applied epinephrine was elevated. A striking topographic feature of the peripheral vascular beds observed in this condition was the relatively greater number of vessels found per unit area of the tissues. Metarterioles, capillaries and collecting venules were all three to four times as numerous as those in the normotensive animals (6).

The changes directly observed with the microscope in the mesenteric capillary vessels of anitnals with renal hypertension are generally in accord with the phenomena present in the conjunctival vascular bed of hypertensive patients. The "hyperplasia" of elements in the capillary bed of the mesentery as found in the renal hypertensive animal was not noted in conjunctival vessels of hypertensive patients, as selected by the methods described above. However, the increased vascular tortuosity, vessel loops and angular capillary topography that was found in $62 \%$ of the patients may represent an analogous phenomenon. Each might conceivably be a morphological pattern of response elicited either by prolonged vasoconstriction or by an increased pressure load on the terminal arteriolar tree. The abnormal vessel patterns in hypertension have been described previously, with other phenomena and "blood sludging," by Lack and co-workers (10). We found tortuosity and looping of vessels less frequently, however, in our cases than reported by these workers and noted a somewhat similar topography of minimal degree in occasional patients without hypertension.

The presence of vasoconstriction with a reduced peripheral flow velocity in the conjunctiva of hypertensive subjects seems at variance with the concept that, in this condition, overall peripheral blood flow is not changed. Assuming that this belief is correct immediately implies that a reduction in flow speed in one region (i.e., the conjunctiva or the mesentery) is compensated by a relative hyperemia with augmented peripheral flow elsewhere. However, it is conceivable that diminished velocity of capillary blood flow per se can exist, and be obscured by the shunting action of arterial and arteriolar-venular arcades that may be located just proximally to the capillary bed. Such vessels are known to exist in the splanchnic area of animals (1). Increased gaseous exchange in the slowed capillary blood may partly mask the relatively unchanged gas content in the shunted blood bypassing the capillaries. Indirect methods of estimating the volume and velocity of actual capillary blood flow might not indicate such a terminal diversion of blood from areas of end-arteriolar vasoconstriction and reduced flow velocity. These latter phenomena, therefore, may possibly be more widespread in the most peripheral vessels in hypertension than is generally believed.

In the present survey we found no absolute correlation between any single feature of the conjunctival vascular system and either the diastolic level of pressure, the severity of symptoms, or the duration of the hypertension. Heightened sensitivity to epinephrine occasionally was found in normo- 
tensive disease. Abnormal vessel arrangements of minor degree occurred in several diseased controls and were well advanced in a hypertensive child of three years of age who was symptom free (Figures 3 and 4). Thus these anatomical changes are not necessarily correlated in degree either with the age of the patient or the presence of symptoms. However, narrowed metarterioles, and prominent spontaneous vasomotion of a predominantly "closed" phase and tissue ischemia were the most frequent findings. They were observed in $90 \%$ of the hypertensive subjects and in none of the controls; and were frequently, but not consistently, of greatest magnitude in subjects with a diastolic pressure of $140 \mathrm{~mm}$. Hg or greater. The tortuosity and coiling of vessels with angular capillary patterns was the second most usual feature.

When all of the criteria used for evaluating the conjunctival capillary vessels were considered together, a composite state of the peripheral vascular bed in hypertension evolved that was not observed in patients with other disease, or in normal subjects. This state was featured by narrowing of the most terminal arterioles, augmented spontaneous vasomotor activity, and frequent elongation, coiling, and tortuosity of the capillaries. Accompanying these phenomena was a heightened metarteriolar and precapillary reactivity to topically applied epinephrine, and a significant reduction in the velocity of peripheral blood flow. This latter was most noticeable in the true capillaries and the collecting venules. The finding that several criteria may permit establishment of an overall peripheral vascular hemodynamic pattern that is inadequately described by any one feature is in accord with the observations on the vascular bed of animals, mentioned previously.

The conjunctival vascular state during hypertension, however, apparently is related to circumstances other than the blood pressure elevation per $s e$, for it was also noted in the four subjects whose hypertension has spontaneously subsided at a period considerably before the examinations were carried out. Clinically, all studies failed to distinguish these individuals from other normotensive subjects without disease, yet on a basis of the findings in the conjunctival capillary bed they could not be separated from patients with a sustained hypertension. It is of interest to speculate whether such functional peripheral vascular changes not only persist following the cessation of prolonged hypertension, but may also occur prior to its onset.

\section{SUM MARY}

1. With suitable apparatus and techniques for measuring vessel function and reaction, studies were made of the conjunctival capillary vessels of subjects with hypertensive vascular disease.

2. When all criteria selected for evaluation were considered together, an overall pattern emerged of certain peripheral vascular abnormalities in hypertension. The total pattern was not found in the normotensive controls. No one feature selected for study could be correlated absolutely either with the age of the patient, the degree of blood pressure elevation, symptomatology or the duration of the illness. This need for a composite of several criteria to establish a peripheral vascular dysfunctional state is in agreement with findings in experimental animals.

3. The abnormal hemodynamics observed in the conjunctival peripheral circulation in essential hypertension consisted of : 1) metarteriolar narrowing ; 2) augmented spontaneous vasomotor activity in precapillary sphincters; and 3) coiling, looping, and tortuosity of many vessels. There was also present a heightened sensitivity of metarterioles and precapillaries to topically applied epinephrine, and a reduced velocity of peripheral blood flow. These features are generally in accord with those which have been described for similar vessels in the splanchnic area of animals with experimental renal hypertension.

4. The conjunctival peripheral vessels of four normotensive subjects who had had an apparently spontaneous remission of previous hypertension displayed the same phenomena found in the conjunctival vascular bed of patients with a sustained hypertension.

\section{REFERENCES}

1. Chambers, R., and Zweifach, B. W., Topography and function of the mesenteric capillary circulation. Am. J. Anat., 1944, 75, 173.

2. Zweifach, B. W., Lee, R. E., Hyman, C., and Chambers, R., The omental circulation in morphinized dogs subjected to graded hemorrhage. Ann. Surg., 1944, 120, 232.

3. Lee, R. E., and Lee, N. Z., The peripheral vascular system and its reactions in scurvy; an experimental study. Am. J. Physiol., 1947, 149, 465. 
4. Chambers, R., Zweifach, B. W., Lowenstein, B. E., and Lee, R. E., Vasoexcitor and -depressor principles as "toxic" factors in experimentally induced shock. Proc. Soc. Exper. Biol. \& Med., 1944, 56, 127.

5. Shorr, E., Zweifach, B. W., and Furchgott, R. F., Hepato-renal factors in circulatory homeostasis. III. The influence of humoral factors of hepatorenal origin on the vascular reactions to hemorrhage. Ann. New York Acad. Sc., 1948, 49, 571.

6. Zweifach, B. W., and Shorr, E., Desoxycorticosterone hypertension in relation to hepatorenal mechanisms. Federation Proc., 1950, 9, 141.

7. Knisely, M., The histophysiology of peripheral vascular beds, in Blood, Heart and Circulation. Ameri- can Association for the Advancement of Science, Washington, 1940, p. 303.

8. Lee, R. E., and Holze, E. A., The peripheral vascular system in the bulbar conjunctiva of young normotensive adults at rest. J. Clin. Invest., 1950, 29, 146

9. Shorr, E., Participation of hepatorenal vasotrophic factors in experimental renal hypertension. Am. J. Med., 1948, 4, 120.

10. Lack, A., Adolph, W., Ralston, W., Leiby, G., Winsor, T., and Griffith, G., Biomicroscopy of conjunctival vessels in hypertension; capillary "hypertension pattern" and occurrence of intravascular clumping (sludged blood) are described. Am. Heart J., 1949, 38, 654 . 